\title{
Better seasonal forecasts for renewable energy industry
}

\author{
Authors: Anton Orlov ${ }^{1}$, Jana Sillmann ${ }^{1}$ and Ilaria Vigo ${ }^{2}$ \\ 1 Center for International Climate Research Oslo (CICERO), Oslo Norway. \\ 2 Barcelona Supercomputer Center, Barcelona, Spain.
}

Anomalous seasons such as extremely cold winters or low wind summers can seriously disrupt renewable energy productivity and reliability. Better seasonal forecasts providing more accurate information tailored to stakeholder needs can help the renewable energy industry prepare for such extremes.

The climate mitigation benefits of clean energy come with great challenges. Compared to conventional fossil-fuel based energy sources, renewable sources, such as wind, solar, and hydropower, are highly weather-dependent. Ambitious mitigation policies aiming to reach a $1.5^{\circ} \mathrm{C}$ target require a radical increase in supplies of clean energy. This implies that total power supply will be more vulnerable to climate-induced weather variability. Balancing the demand and supply of intermittent renewable energy sources thus imposes a big challenge. Consequently, renewable energy technologies must become more resilient to climate variability and high impact events.

Weather and climate variability affect the demand as well as supplies of renewable energy. High and low temperatures imply a high energy demand for cooling and heating, respectively ${ }^{1}$. The relationship between electricity consumption and temperature is non-linear ${ }^{2}$ : at a certain threshold level, an increase in temperatures results in a step increase in energy demand for cooling in summer. For instance, in August 2003, in July 2010 and in June-August 2015, Europe experienced severe heat waves 
${ }^{3}$, which imposed an additional pressure on the power demand for cooling ${ }^{4}$. Similarly going below the thermal comfort threshold in winters leads to a sudden higher energy demand for heating ${ }^{5}$.

On the supply side, fluctuations in solar radiation and wind speed determine the power generation from solar and wind, respectively ${ }^{6}$. For instance, the USA experienced low surface wind speeds and thereby a reduction in wind power among some wind farms during the first quarter of 2015. This wind drought in the USA was to a large extent caused by high sea surface temperatures in the tropical Pacific 7. Variability in temperatures and precipitation can also affect runoff and thereby hydropower generation ${ }^{8}$, as can the occurrence of climate extremes such as droughts and floods ${ }^{9}$.

Climate change has the potential to bring extreme variability to both demand and supply of the electricity equation. These kinds of changes also result in adverse economic implications for renewable power producers, particularly if they are unforeseen.

\section{Climate change increases seasonal variability}

While climate models are usually too coarse and not meant to simulate specific weather events, they can inform us about the increased chances of more extreme seasons at the regional level. Although extreme weather events, such as heat waves and cold spells, are natural phenomena of the climate system, growing scientific evidence indicates that anthropogenic climate change has a significant impact on the seasonal cycle of surface temperatures ${ }^{10}$. Research reveals that by the end of the $21^{\text {st }}$ century extreme precipitation could shift considerably in many regions from summer and early fall towards fall and winter, being especially pronounced in Northern Europe and North-Eastern America 11. Heat waves, which are one of the most studied extreme events, are expected to become more intense, more frequent, and longer lasting in Europe and North America.

On the global scale, the duration of heat waves is expected to increase, while cold spell durations will decline ${ }^{12}$. Even under a $2^{\circ} \mathrm{C}$ world, the probability of warm periods lasting longer than two weeks has been shown to rise significantly in the Northern Hemisphere mid-latitude area ${ }^{13}$. Mediterranean 
droughts are expected to start earlier and last longer ${ }^{14}$. Furthermore, reductions in the mean sealevel pressure will lead to more storms along North Sea coastal regions, and there are indications of significant changes in the patterns of heavy winter and summer precipitation across Europe ${ }^{14}$. These projections for seasonal changes need to be complemented by seasonal forecasts to be utilized for decision-making and planning on shorter timescales.

\section{Incorporating forecasts in planning}

To bridge the gap between long term climate change projections and common decision-making timeframes of the energy sector (i.e. a few weeks to a few years ahead), the climate modelling community has invested considerable scientific effort and resources in developing probabilistic approaches to subseasonal to seasonal climate predictions ${ }^{15}$. For instance, seasonal forecasts of wind can be used to estimate the capacity factor, which quantifies the impact of weather variability, such as wind, solar radiation or temperature, on production ${ }^{16}$. Probabilistic forecasts of upcoming extremes events could help energy producers, traders, and transmission companies in strategic planning, investment and financial decisions ${ }^{17}$. Predicting anomalous seasons is important for scheduling operations and maintenance (O\&M) activities as well as for budget planning. Seasonal forecasts could be useful in managing hydropower reservoirs; releasing water from reservoirs, which is not used for energy production, is considered a production loss and better forecasts of seasonal water demand downstream can allow for better water storage and release management. Predicting annual seasonality plays a crucial role in electricity price forecasting.

In each of these cases, specific information about how hot, cold, humid, dry or windy a particular upcoming season would be, is information that can be critical towards estimating wind or solar energy production potential, risk of disruption and damage from storms, rainfall runoffs and seasonal water flows among other variables. Better foreknowledge of these variables can improve decision-making in renewable energy business and finance. 
Sub-seasonal to seasonal (S2S) forecasts thus aim to bridge the timescale gap between short-range weather forecasts and long-range climate projections, thereby offering potential benefits to the renewable energy stakeholders who need information at the seasonal or sub-seasonal scale ${ }^{27}$. Better forecasts could help renewable energy producers plan their production and curtailment with greater accuracy and over longer timeframes, leading to improved performance of renewable energy businesses. This in turn will make renewable energy business more competitive, attracting more investments and facilitating a smoother transition towards a low carbon economy. However, to make these forecasts more useful to decision makers, the decision-making process in the renewable energy industry and its demand for forecast certainty needs to be better understood and taken into account by the scientists producing the forecasts.

Decision-making in the energy sector is complex. Decision makers deal with many types of uncertainties of which climate variability is only one. Decision makers rely on forecasts only when the forecasts can achieve certain probability thresholds (Fig. 1). Thresholds vary by the type of business, type of decision, and the individual risk aversion. They could also change over time depending on when a decision should be made and how the predictive capability evolves. The utility of the forecast depends upon the type, need and timing of the forecast. 


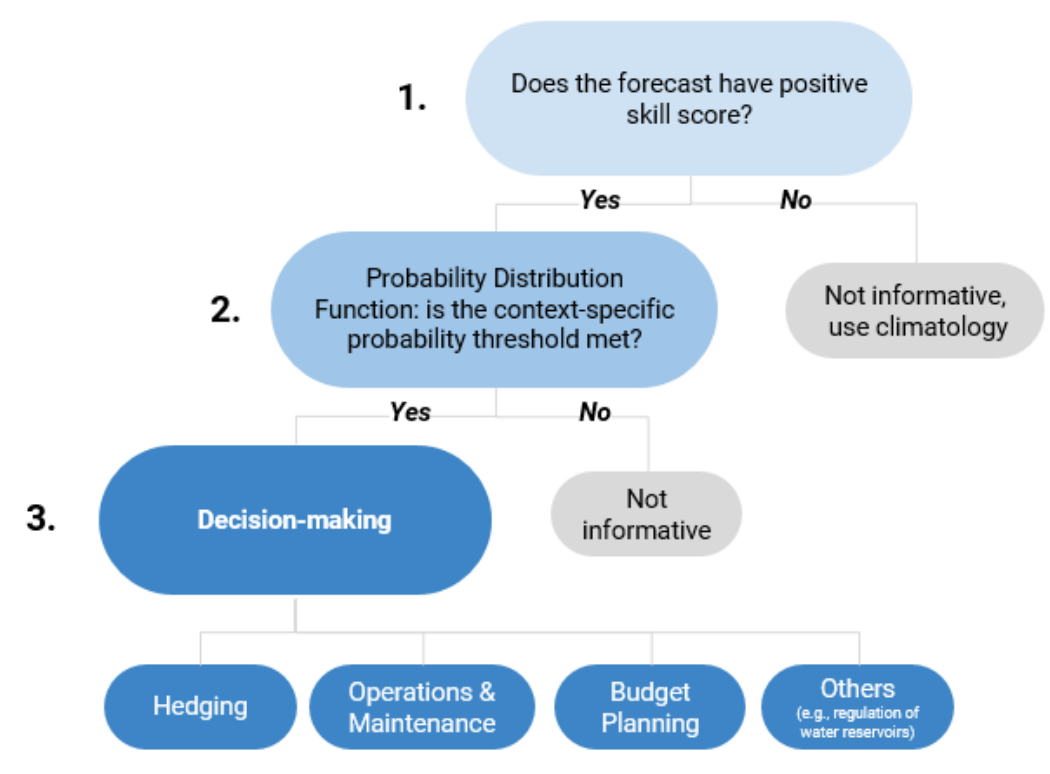

Fig. 1. Decision tree explaining user choices based on skill scores and probability distribution functions. There are several steps involved from step 1. Decision makers look at the skill score, and if deemed informative or relevant to step 2. Decision makers look at the probability distribution of the forecast compared to the climatology of the weather variable of interest (e.g. wind or temperature), and if this is informative that can be incorporated in the decision-making either as qualitative or quantitative information in step 3. Predictive skill scores measure the accuracy of forecasts. A positive (negative) value of skill scores indicates that the forecast has higher (lower) accuracy than climatology, which relies on past observations and is usually the basis for decision-making in the renewable energy industry. Probability distributions of a weather variable provided by seasonal forecast models can indicate if there is a higher or lower likelihood of an upcoming season to be extreme compared to the climatology.

\section{Seasonal forecast utility for stakeholders}

A lot of the financial risks of sub-seasonal and seasonal variation cannot be passed by producers (or utilities) to end-users. Thus, to cope with the weather and climate related uncertainties, producers and traders of electricity use financial instruments, such as power futures, to hedge financial risks. The 
effectiveness of these financial instruments depends highly on the predictability of the weather and climate.

Incorrectly predicted weather anomalies can result in substantial economic losses. For example, in January 2017, an abnormal cold weather spell created an increase in demand for electricity. Supplemented by low wind speed and low solar generation in most of Europe at the time, the cold spell resulted in high wholesale electricity prices. In France, a high demand for electricity was expected but the forecast, and consequently the market, overestimated the magnitude of the anomaly. The power futures settlement price went up to $170 \mathrm{EUR} / \mathrm{MWh}$, eventually settling down to approximately 90 EUR/MWh (Fig. 2). At the same time, there was no clear signal of the upcoming anomaly in the power futures settlement prices in Germany until one week before the delivery of the electricity. The extreme event was not predicted in Germany, and therefore the increase in wholesale prices was unexpected (Fig. 2). Traders would have benefitted from accurate sub-seasonal forecast, allowing them to improve their hedging strategies both in France and Germany. In Germany, a trader could have purchased energy before the rise in price. In the French case accurate sub-seasonal forecasts could have adjusted traders' expectations, for instance, preventing them from buying energy when the price was highest.

In general, decision makers tend to be rather risk-averse towards action; they are more wary of taking wrong decisions due to misleading information than gaining from using correct forecasts. Thus, providing information about the reliability and uncertainties entailed in S2S forecasts is vital for a better informed decision-making. If S2S forecasts can be made quantifiably more reliable, they represent a valuable resource for risk management of extreme events. This is even more the case if the S2S forecasts come with such quantified certainty that they can directly be integrated into estimations for solar, wind and hydro generation, and electricity demand planning. 


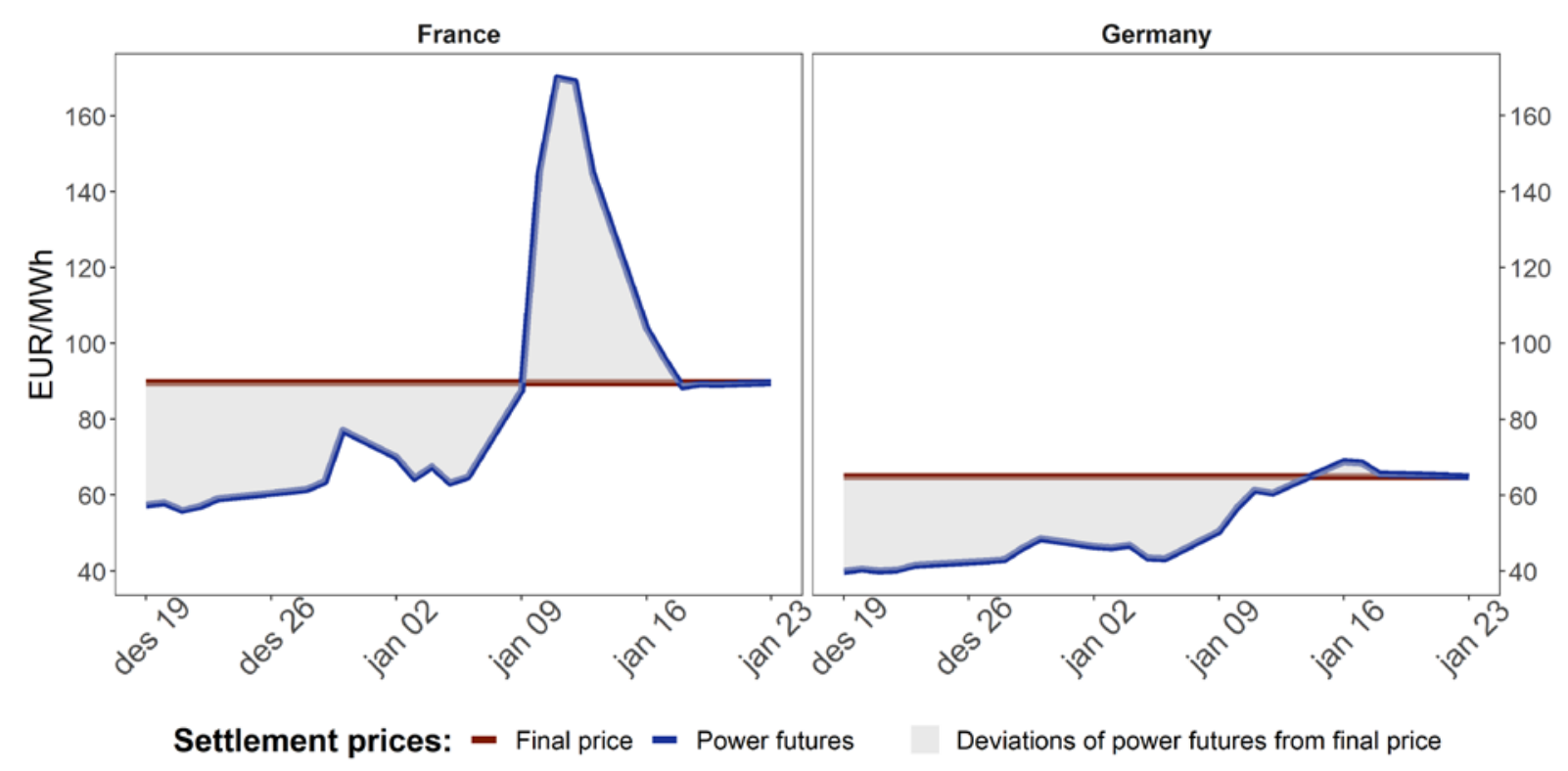

Fig. 2: Final and power futures settlement prices in Germany and France for week 3 in 2017, a severe cold spell period. Delivery of electricity for the calendar week 3 in 2013 was traded a few weeks lead at futures contracts. The blue curves show the French Financial Baseload Future settlement price (EUR/MWh) and German Phelix DE/AT Baseload Future settlement price (EUR/MWh). Power futures settlement prices are the prices at which electricity was traded before the delivery period, while the final settlement price (red line) is the final price for the week 3 product. The final settlement price equals to an average of day-ahead auction prices of a week before the delivery (i.e., Jan 16-22, 2017). The delivery period started on Jan 23, 2017. Any deviation of power futures settlement prices from the final settlement price is due to market's expectations. The price is overestimated (underestimated) when power futures settlement prices are above (below) the final settlement price. In this example anomalous weather conditions played an important role in the deviations (grey area). Sub-seasonal forecasts could have allowed a trader to anticipate these deviations, adjust her/his expectations accordingly and therefore improve the hedging strategy. Data from ${ }^{18}$.

S2S forecasting is still at an early stage, and it is very challenging to provide accurate predictions. Nonetheless, substantial progress has been made in the last decade. For example, the seasonal forecast ensemble successfully reproduced the observed patterns of the influence of the North Atlantic Oscillation on changes in temperatures and wind speed over Europe ${ }^{19}$. Current S2S models are able to predict the evolution of some large-scale extreme events for several weeks ahead, such as the 2010 
Russian heat wave and tropical storms ${ }^{20}$. Progress has also been made in providing informative S2S climate predictions for wind speed ${ }^{15}$. Yet the economic value of S2S forecasts has not been sufficiently investigated.

Despite considerable progress in the development of S2S forecasts, there are still many challenges to overcome. There are large uncertainties at regional scales and short time scales (i.e. 1-10 years ahead) on how climate change will affect the frequency and intensity of extreme events ${ }^{21}$. However, the utility of the forecast also depends on how the information is provided (e.g. raw data, visual, experts' support, etc.) and the specific needs of decision makers (e.g. qualitative vs. quantitative information, level of detail or required skill of forecast). Many renewable energy companies are exploiting climate information, but normally they still do not make quantitative use of $\mathrm{S} 2 \mathrm{~S}$ forecasts ${ }^{22}$. The main barriers to wider implementation of climate predictions into decision support systems are: different terminologies used by climate scientists and users, difficulties with incorporating probabilistic outcomes into decision-making, the quality of climate predictions and the fact that the assessment of benefits is often based on short-term considerations while the inclusion of climate predictions into decision-making tends to have long-term benefits ${ }^{23}$.

A stronger collaboration between weather and climate communities as well as stakeholder engagement are needed to make further progress in making S2S forecasts more useful for the energy sector. This should involve not just reducing relevant uncertainties within models but also making S2S forecast tools more relevant and accessible for decision-making ${ }^{24}$. To achieve this, more collaborative studies involving stakeholders making financial and economic decisions are needed to increase the sophistication and applicability of the analysis for real life decision-making. In this way, S2S forecasting can hopefully make seasonal extremes a little more predictable and therefore their impacts less severe. 


\section{Acknowledgement}

The authors acknowledge funding from the EU Horizon 2020 project "Sub-seasonal to seasonal climate forecasting for energy (S2S4E)" (GA776787).

\section{References:}

1. Cronin, J., Anandarajah, G. \& Dessens, O. Climate change impacts on the energy system: a review of trends and gaps. Clim. Change 151, 79-93 (2018).

2. Bessec, M. \& Fouquau, J. The non-linear link between electricity consumption and temperature in Europe: A threshold panel approach. Energy Econ. 30, 2705-2721 (2008).

3. Russo, S., Sillmann, J. \& Fischer, E. M. Top ten European heatwaves since 1950 and their occurrence in the coming decades. Environ. Res. Lett. 10, 124003 (2015).

4. EC. Quarterly report on European electricity markets. Market observatory for Energy. DG Energy. Volume 8, Issue 3. Third quarter of 2015. (2015).

5. Sailor, D. J. Relating residential and commercial sector electricity loads to climate-evaluating state level sensitivities and vulnerabilities. Energy 26, 645-657 (2001).

6. Staffell, I. \& Pfenninger, S. The increasing impact of weather on electricity supply and demand. Energy 145, 65-78 (2018).

7. Lledó, L., Bellprat, O., Doblas-Reyes, F. J. \& Soret, A. Investigating the Effects of Pacific Sea Surface Temperatures on the Wind Drought of 2015 Over the United States. J. Geophys. Res. Atmospheres 123, 4837-4849 (2018).

8. Shu, J., Qu, J. J., Motha, R., Xu, J. C. \& Dong, D. F. Impacts of climate change on hydropower development and sustainability: a review. IOP Conf. Ser. Earth Environ. Sci. 163, 012126 (2018).

9. Kumar, A. et al. Hydropower. In IPCC Special Report on Renewable Energy Sources and Climate Change Mitigation [O. Edenhofer, R. Pichs-Madruga, Y. Sokona, K. Seyboth, P. Matschoss, S. 
Kadner, T. Zwickel, P. Eickemeier, G. Hansen, S. Schlömer, C. von Stechow (eds)], Cambridge University Press, Cambridge, United Kingdom and New York, NY, USA. (2011).

10. Santer, B. D. et al. Human influence on the seasonal cycle of tropospheric temperature. Science 361, eaas8806 (2018).

11. Marelle, L., Myhre, G., Hodnebrog, $\varnothing$., Sillmann, J. \& Samset, B. H. The Changing Seasonality of Extreme Daily Precipitation. Geophys. Res. Lett. 45, 11,352-11,360 (2018).

12. Sillmann, J., Kharin, V. V., Zwiers, F. W., Zhang, X. \& Bronaugh, D. Climate extremes indices in the CMIP5 multimodel ensemble: Part 2. Future climate projections. J. Geophys. Res. Atmospheres 118, 2473-2493 (2013).

13. Pfleiderer, P., Schleussner, C.-F., Kornhuber, K. \& Coumou, D. Summer weather becomes more persistent in a $2^{\circ} \mathrm{C}$ world. Nat. Clim. Change 1-6 (2019) doi:10.1038/s41558-019-0555-0.

14. Beniston, M. et al. Future extreme events in European climate: an exploration of regional climate model projections. Clim. Change 81, 71-95 (2007).

15. Soret, A. et al. Sub-seasonal to seasonal climate predictions for wind energy forecasting. J. Phys. Conf. Ser. 1222, 012009 (2019).

16. Lledó, LI., Torralba, V., Soret, A., Ramon, J. \& Doblas-Reyes, F. J. Seasonal forecasts of wind power generation. Renew. Energy 143, 91-100 (2019).

17. Dutton, J. A., James, R. P. \& Ross, J. D. Probabilistic Forecasts for Energy: Weeks to a Century or More. in Weather \& Climate Services for the Energy Industry (ed. Troccoli, A.) 161-177 (Springer International Publishing, 2018). doi:10.1007/978-3-319-68418-5_12.

18. EEX. European Energy Exchange. Market Data. (2017).

19. Clark, R. T., Bett, P. E., Thornton, H. E. \& Scaife, A. A. Skilful seasonal predictions for the European energy industry. Environ. Res. Lett. 12, 024002 (2017).

20. Vitart, F. \& Robertson, A. W. The sub-seasonal to seasonal prediction project (S2S) and the prediction of extreme events. Npj Clim. Atmospheric Sci. 1, 3 (2018).

21. Tippett, M. K. Extreme weather and climate. Npj Clim. Atmospheric Sci. 1, 1-2 (2018). 
22. Vigo, I., Orlov, A., Hernández, K., Aaheim, H.-A. \& Manrique-Suñén, A. Economic gains from using S2S forecasts in energy producers' decision-making by analysing relevant case studies.

Deliverable D2.2 of the S2S4e project. (2019).

23. Terrado, M. et al. The Weather Roulette: A Game to Communicate the Usefulness of Probabilistic Climate Predictions. Bull. Am. Meteorol. Soc. 100, 1909-1921 (2019).

24. Mariotti, A., Ruti, P. M. \& Rixen, M. Progress in subseasonal to seasonal prediction through a joint weather and climate community effort. Npj Clim. Atmospheric Sci. 1, 4 (2018). 